\title{
Structural And Electrical Properties Of Silicon NITRIDE CERAMIC
}

\author{
Hosneara $^{1}$, A. Hasnat ${ }^{2 *}$ and A. H. Bhuyan ${ }^{3}$. \\ ${ }^{1}$ National University, Bangladesh, \\ ${ }^{2}$ Departmet of Physics, Jagannath University, Dhaka, Bangladesh and ${ }^{3}$ Dept of Physics, Bangladesh \\ University of Engineering and Technology (BUET), Dhaka, Bangladesh, \\ E-mail: mahasnat.phy@gmail.com
}

\begin{abstract}
The effects of structural properties on the d.c. and a.c. electrical properties of different weight gain reaction bonded silicon nitride (RBSN) have been studied in this work. The degree of nitridation is assessed by the 'weight gain' of the ceramic, the percentage by which the weight is increased in the nitriding reaction. From X-ray diffraction (XRD) patterns, it is observed that a higher degree of nitradation sample has strong $\alpha$-silicon nitride peaks. Intensity of $\alpha$-silicon nitride peaks decreases with decreases weight gain. The higher degrees of nitridation, the samples have less significant Si peak. $X R D$ patterns were recorded to calculate the lattice parameters of RBSN. The lattice parameters for three weight gain RBSN samples are found to be $a=b=$ $7.7727 \AA, c=5.6565 \AA$ (26\% weight gain), $a=b=$ $7.6272 \AA, c=5.6374 \AA$ (42\% weight gain) and $a=b=7.6158 \AA, c=5.7732 \AA$ (58.27\% weight gain) and are in good agreement with the reported values from XRD patterns. Porosity (\%) and surface morphology was observed by SEM.
\end{abstract}

Keywords: Silicon nitride ceramic, electrical properties and structural properties.

\section{Introduction}

Silicon nitride $\left(\mathrm{Si}_{3} N_{4}\right)$ is one of the most promising ceramic materials was developed in the 1960's and $70 \mathrm{~s}$ in a search for fully dense, high strength and high toughness materials. As a high temperature engineering ceramic attracted more attention because of its promising thermo mechanical properties such as high temperature mechanical strength, durability, thermal shock resistance chemical corrosion resistance etc. Also $\mathrm{Si}_{3} N_{4}$ is a potentially high thermal conductivity material with an intrinsic value of up to $200 \mathrm{Wm}^{-1} \mathrm{~K}^{-1}$. Silicon nitride is being considered for a wide variety of structural application, hot flow-path components for gas turbine engine, turbocharger rotors and diesel engine components. A major application of silicon nitride ceramic aimed in the construction of a gas turbine engine. If the target is realized, fuel saving of up to $40 \%$ for a given power output should be possible. In addition, the engine would be lighter and constructed from cheap and readily available materials [1]. Although the ultimate goal of a ceramic has never been achieved, silicon nitride has been used in a number of industrial applications, such as engine components, bearings and cutting tools. $\mathrm{Si}_{3} \mathrm{~N}_{4}$ Can be hot pressed (HPSN) to full density such materials exhibit good low temperature mechanical properties. However, because a hotpressing aid must be used, the high temperature properties may be severally degraded (the severity depends on the type and amount of additive). Furthermore $\mathrm{Si}_{3} N_{4}$ can only be hot pressed in simple configuration. While diamond - grinding might be used to form complex components, it cost would be prohibited for most application. $\mathrm{Si}_{3} \mathrm{~N}_{4}$ also can be cold formed and sintered (SSN) to near fully density however, sintering aids must be used in large quantities which can lead to the deterioration of high temperature properties as in the case of hotpressed $\mathrm{Si}_{3} N_{4}$ [2-3]. The most commonly used additives are magnesium oxide (MgO) and yttrium oxide $\left(\mathrm{Y}_{2} \mathrm{O}_{3}\right)$, which can be used separately, in combination or with aluminum oxide $\left(\mathrm{Al}_{2} \mathrm{O}_{3}\right)$. Interest in RBSN as a hightemperature engineering ceramics was first shown about twenty years ago by Norman Parr of the admiralty Materials laboratory and Popper 


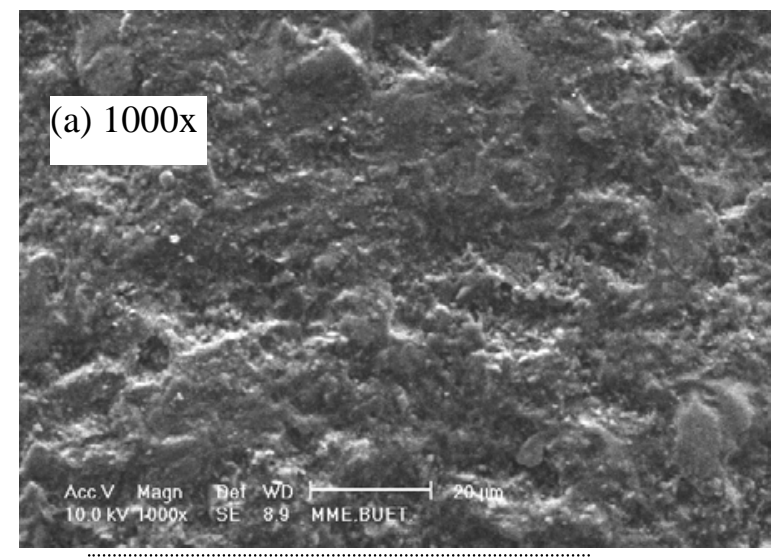

(a) $26 \%$ weight

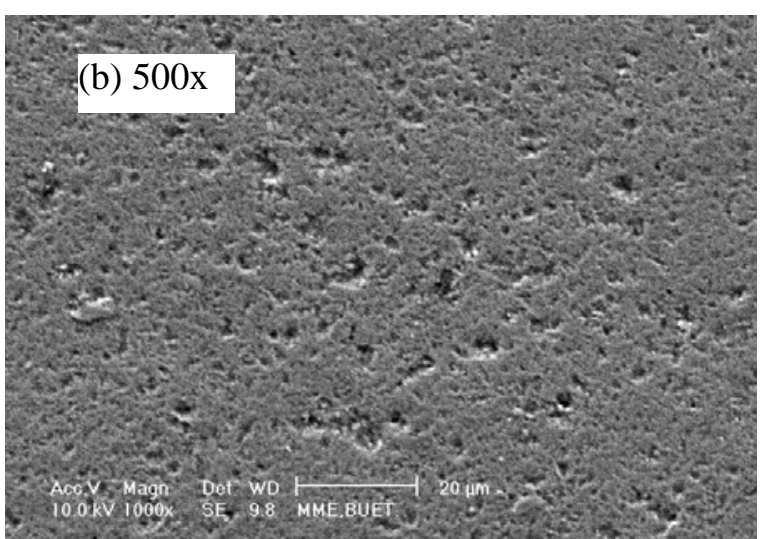

(b) $42 \%$ weight gain

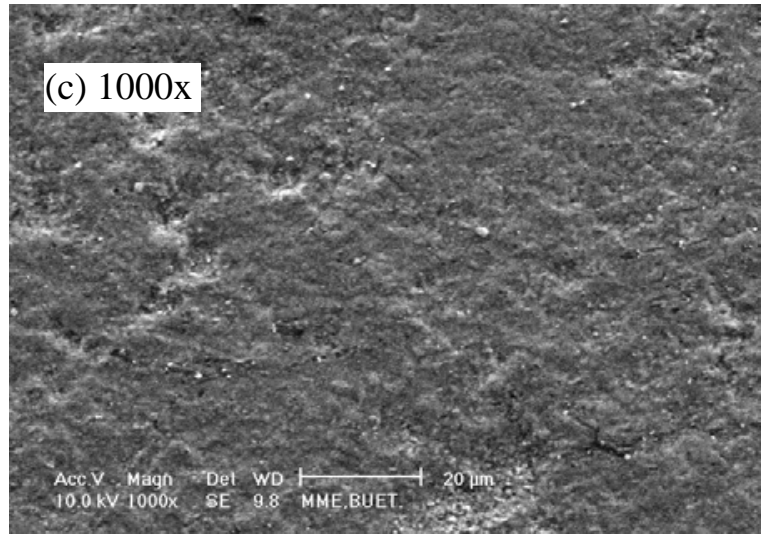

(c) $58.27 \%$ weight gain (1000 magnification).

Fig.1: SEM micrographs of the RBSN samples

[4-5] of the British Ceramic Research Association, both in United Kingdom. RBSN produced by reaction bonding of silicon powder compacts is cheaper ompared to sintered $\mathrm{Si}_{3} N_{4}$, because the price of $\mathrm{Si}$ powder is much lower than that of $\mathrm{Si}_{3} N_{4}$ powder. Reaction bonding processes generally require lower fabrication temperatures than hot pressing and pressure less sintering which is a potential advantage for processing ceramic-matrix composites where high temperatures can damage the reinforcement phase [6-7].

\section{Materials and Methods}

From the $\mathrm{XRD}$, it is found that the density increases and porosity decreases as weight gain increases. Scanning Electron Microscope (SEM) was used to see surface morphology. The D.C. measurement set up is shown in Fig. 1. For D.C. electrical measurement of RBSN, electroding, Keithly 614 electrometer, D.C. power supply, specimen chamber, and heating coil are used. A Brief description of these instruments is given below. The Agilent 4192 A Impedance Analyzer $(5 \mathrm{~Hz}-13 \mathrm{MHz})$ was used in the A.C. measurement. This instrument can measure various parameters; resistance (R), Conductivity (G) etc. The following ac electrical parameters will be measured at different frequencies and temperatures: i) ac capacitance $\left(\mathrm{C}_{\mathrm{p}}\right)$ and ii) ac conductance $\left(G_{p}\right)$. Then ac electrical conductivity $\left(\sigma_{\mathrm{ac}}\right)$, dielectric constant $\left(\epsilon^{\prime}\right)$ and loss tangent $(\tan \delta)$ will be calculated. These measurements were taken against the frequency value from $5 \mathrm{~Hz}$ to $13 \mathrm{MHz}$. The arrangement of A.C.measurement is shown in Fig.8. During the observations for different frequencies of a sample a particular temperature was maintained. The calculations were performed using the 
observed values of conductance $\left(G_{p}\right)$ and capacitance $\left(\mathrm{C}_{\mathrm{p}}\right)$ at different frequencies and temperatures by the following relations .for conductivity $\sigma_{\mathrm{ac}}=\left(\mathrm{d} / \mathrm{A} \mathrm{G}_{\mathrm{p}}\right)$, where $\mathrm{G}_{\mathrm{p}}=$ conductance, $\mathrm{d}=$ thickness of the sample and $\mathrm{A}=$ area of the electrode area. For dielectric constant $\epsilon^{\prime}=C_{p} \times\left(d / A \in_{0}\right)$, where $C_{p}=$ capacitance of the sample, $\epsilon_{0}=$ permittivity of free space .For dielectric loss tangent $\tan \delta=\mathrm{G}_{\mathrm{p}} /\left(2 \pi \mathrm{fC} \mathrm{C}_{\mathrm{p}}\right)$., where $\mathrm{f}=$ linear frequency. The Bragg's law is the cornerstone of XRD analysis; it allows us to make accurate quantification of the results of experiments carried out to determine crystal structure. It was formulated in 1912 by W L
Bragg, in order to explain the observed phenomenon that crystals only reflected X-rays at certain angles of incidence. For morphology investigation, the different weight gain RBSN samples are examined with scanning electron microscope Philips XL30 (Nether land). A study on microstructure is done by SEM observation.

\section{Results and Discussion \\ 3.1 SEM Analysis}

SEM micrographs of different RBSN samples are shown in Fig. 1. and Fig. 2. of 100x and 500x magnification respectively.

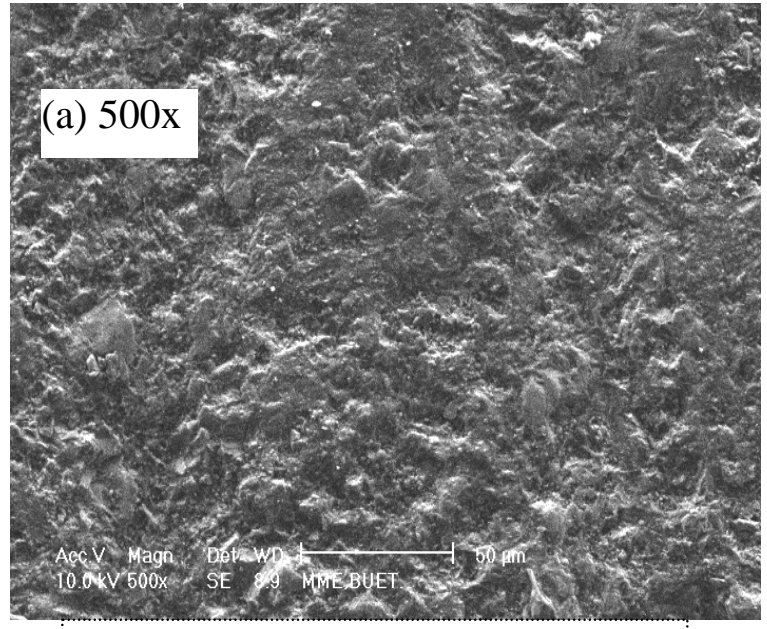

(a) $26 \%$ weight gain

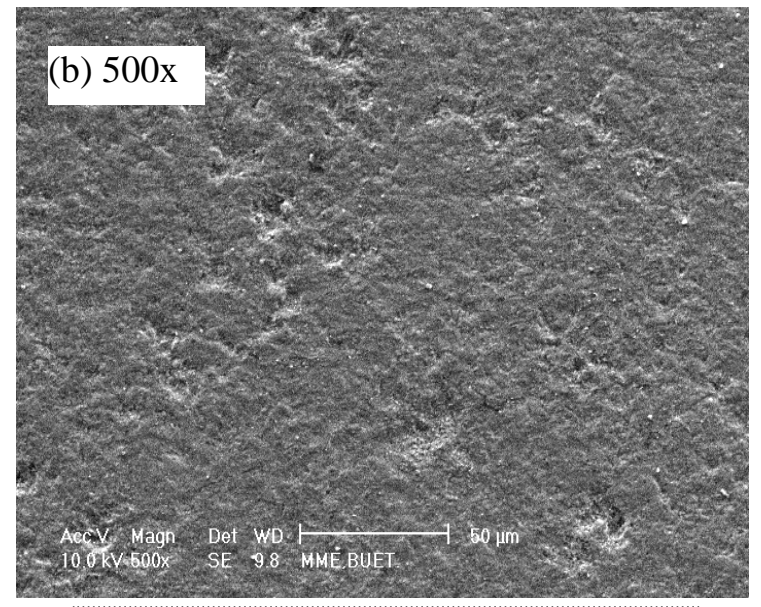

(b) $42 \%$ weight gain

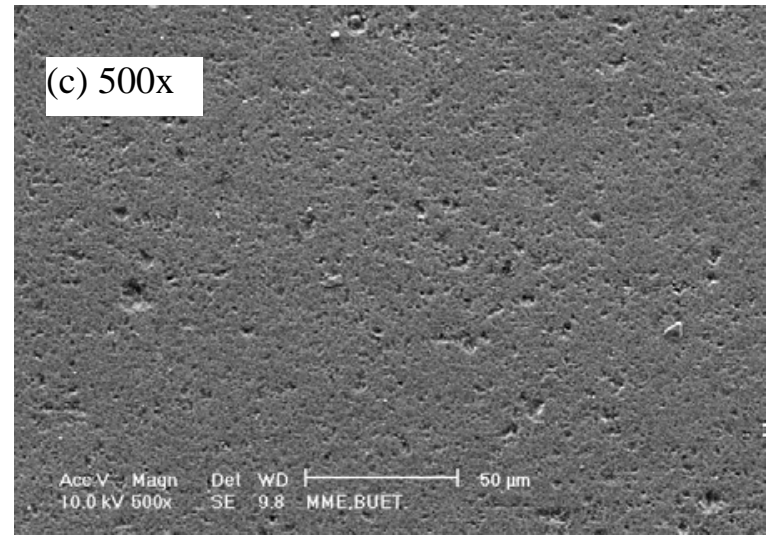

(c) $58.27 \%$ weight gain (500 magnifications).

Fig.2: SEM micrographs of the RBSN samples 


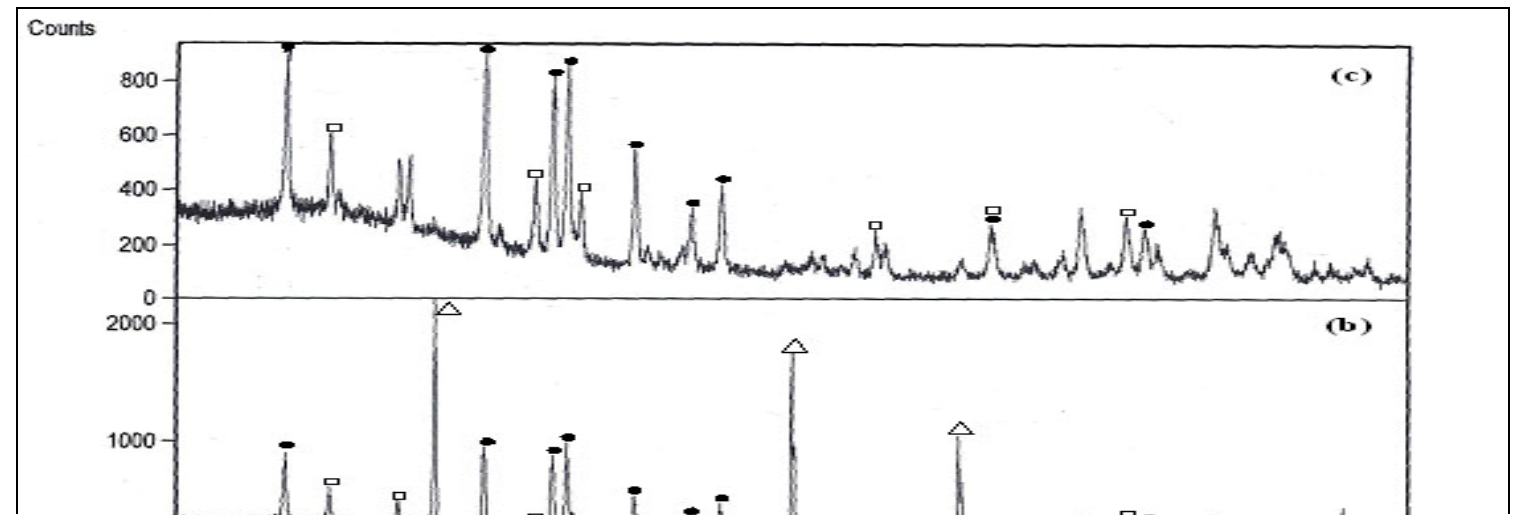

Fig: 3: XRD Patterns of (a) 26\% weight gain, (b) $42 \%$ weight gain, (c) $58.27 \%$ weight gain RBSN

The samples are exhibited a typical development of RBSN with porous microstructure. The micrographs of $26 \%$ weight gain sample in Fig. 1.(a) \& 2.(a), it is seen that the surface is rough and porous. The developments of large pores are shown in Fig. 1.(a) \& 2.(a), for $26 \%$ weight gain sample. From SEM micrographs of different weight gain samples, it is observed that the porosity decreases with increasing weight gain and the surface of the samples become smoother. These facts support the observations by SEM.

\subsection{XRD Analysis}

X-ray diffraction (XRD) patterns of different weight gain RBSN samples are presented in Fig. 3 . The XRD pattern of $26 \%$ weight gain sample has strong silicon peaks and less significant $\alpha$ and $\beta$ - silicon nitride peaks. The XRD patterns of $42 \%$ weight gain sample has silicon and $\alpha$ and $\beta$ silicon nitride peaks. The XRD patterns of $58.27 \%$ weight gain sample exhibits $\beta$-silicon nitride peaks and strong $\alpha$ - silicon nitride peaks. It could be noticed that there is increase in peak intensity of $\alpha$ - and $\beta$-silicon nitride with the increase of weight gain \%. It is observed that the peak intensity of $\alpha$ - silicon nitride phase stronger in $58.27 \%$ weight gain sample than those in other samples. A distinct feature of the nitridation of $\mathrm{Si}$ is that both $\alpha$ and $\beta$ phases are always simultaneously formed, that is, the $\mathrm{Si}_{3} \mathrm{~N}_{4}$ product usually consist of both $\alpha$ and $\beta$ phases. Moulson [4] proposed that major growth of $\beta$ phase occurs in the liquid phase and to a minor extent, as a result of the reaction of solid silicon and nitrogen and the growth of $\alpha$-phase occurs by vapor phase reaction. $\alpha$ - and $\beta-\mathrm{Si}_{3} \mathrm{~N}_{4}$ are polymorphs of $\mathrm{Si}_{3} \mathrm{~N}_{4}$ with $\alpha-\mathrm{Si}_{3} \mathrm{~N}_{4}$ having the slightly higher free energy at the formation temperature. RBSN sample crystallizes in the hexagonal system. From XRD results, lattice parameters were calculated using the formula for hexagonal system. The calculated lattice parameters a, b and c are shown in table-1. Experimental values of lattice parameters are very close to the reported standard values [7] as mentioned below. The volumes of the unit cells of different samples are given in Table 1.

Table 1: Lattice Parameters of Different Weight Gain RBSN Samples

\begin{tabular}{|l|c|c|c|c|}
\hline \multirow{2}{*}{ Samples of RBSN } & \multicolumn{2}{|c|}{ Experimental lattice parameter } & \multirow{2}{*}{$\begin{array}{c}\text { Volume of unit cell } \\
\AA^{3}\end{array}$} \\
\cline { 2 - 4 } & $\mathrm{a}(\AA)$ & $\mathrm{b}(\AA)$ & $\mathrm{c}(\AA)$ & \\
\hline $\begin{array}{l}\text { Reported standard values } \\
\text { for } \mathrm{Si}_{3} \mathrm{~N}_{4}[6]\end{array}$ & 7.7541 & 7.7541 & 5.6217 & 292.73 \\
\hline $26 \%$ weight gain & 7.7727 & 7.7727 & 5.6565 & 341.73 \\
\hline 42\% weight gain & 7.6272 & 7.6272 & 5.6374 & 327.95 \\
\hline $58.27 \%$ weight gain & 7.6158 & 7.6158 & 5.7732 & 334.85 \\
\hline
\end{tabular}


Porosity were calculated from XRD patterns by using the formula, $\mathrm{p}(\%)=\frac{\rho_{t h}-\rho_{\exp }}{\rho_{t h}} \times 100 \%$, Where $\rho_{t h}=\frac{1}{V_{\exp }} \cdot n \cdot \frac{M_{A}}{N_{A}}$, Here, $\mathrm{V}_{\exp }=\mathrm{a}^{2} \mathrm{c}, \mathrm{n}=$ number of atoms per unit cell, $\mathrm{M}_{\mathrm{A}}=$ Atomic weight of silicon nitride, $\mathrm{N}_{\mathrm{A}}=$ Avogadro's number and $\rho_{\exp }=\frac{M(\text { mass })}{V(\text { volume })}$

Porosity of different weight gain samples are shown in Table 2.

Table 2: Porosity and Density of Different Weight Gain RBSN Samples

\begin{tabular}{|c|c|c|c|c|}
\hline Samples of RBSN & $\begin{array}{c}\text { Experimental } \\
\text { density }\left(\rho_{\exp }\right)\end{array}$ & $\begin{array}{c}\text { Theoretical } \\
\text { density }\left(\rho_{\text {th }}\right)\end{array}$ & Density & Porosity (\%) \\
\hline $\begin{array}{c}\text { Reported Value for RBSN(fully } \\
\text { nitrided) [4] }\end{array}$ & & & 2.56 & $20-25$ vol \% \\
\hline 26\% weight gain & 1.998 & 2.835 & & 29.54 \\
\hline 42\% weight gain & 2.108 & 2.721 & & 22.53 \\
\hline $58.27 \%$ weight gain & 2.181 & 2.776 & & 21.45 \\
\hline
\end{tabular}

It is seen that porosity decreases with increasing weight gain.

\subsection{Current Density}

The variation of voltage of current density for $26 \%$ weight gain sample is shown in Fig 4. From this Fig, it is observed that current density increases with increasing voltage. The applied voltage is 0 to $5 \mathrm{~V}$. The current density is weakly dependent on temperature.

Current density as function of applied voltage for $42 \%$ weight gain sample as show in Fig. 5(a). It is shown that current density increase with increasing voltage and is slightly increases with temperature. There also the applied voltage is 0 to $5 \mathrm{~V}$. The variation of current density as function voltage for $58.27 \%$ weight gain sample is shown in Fig. 5 (b). From this graph it is found that current density increases with increasing voltage and temperature. Current density at higher temperature $(423 \mathrm{~K})$ is $10^{1}$ orders higher than that of lower temperature (298K).Current density at different voltages follows the $\mathrm{J} \propto \mathrm{V}^{\mathrm{n}}$ law.

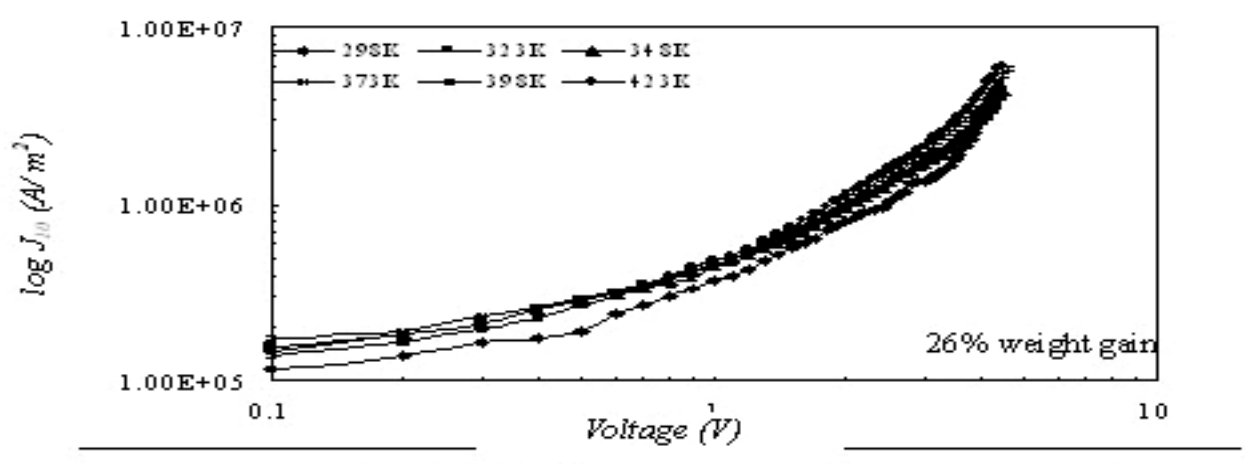

Fig-4: Current density as a function of applied voltage 

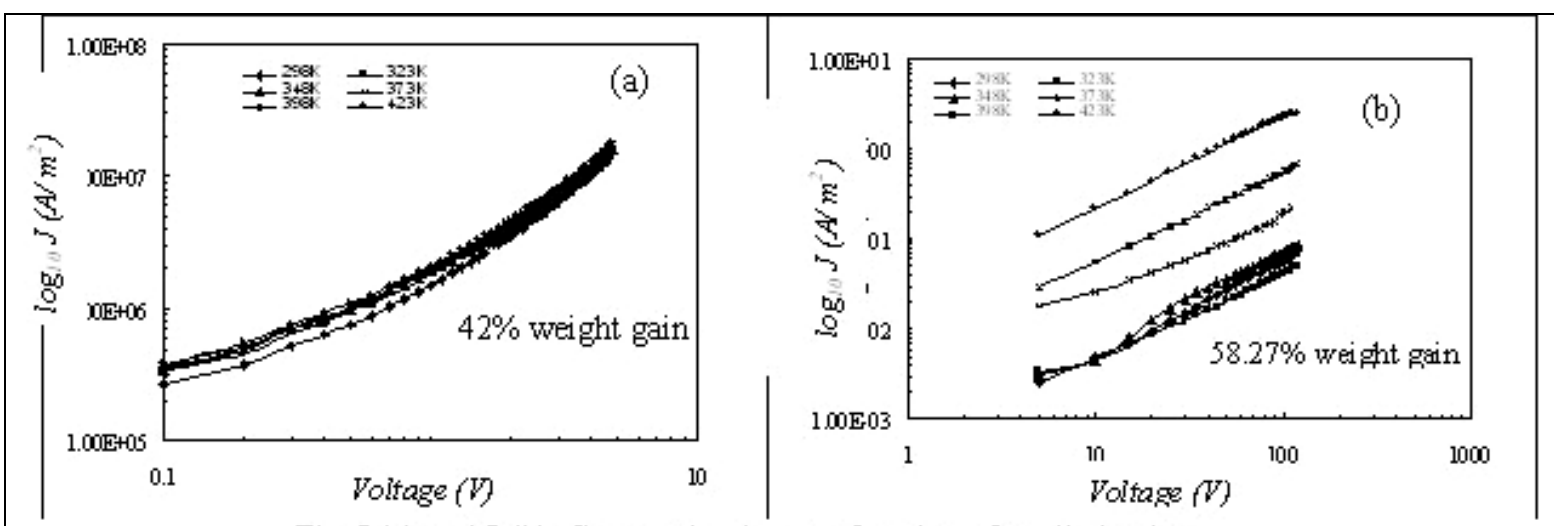

Fig-5 (a) and 5 (b): Current density as a function of applied voltage

Table 3: The value of ' $n$ ' for Different RBSN Samples

\begin{tabular}{|c|c|c|}
\hline Samples & \multicolumn{2}{|c|}{$\mathrm{n}$ values } \\
\hline \multirow{2}{*}{$26 \%$ weight gain } & $0-1.2 \mathrm{~V}$ & $1.3-5 \mathrm{~V}$ \\
\cline { 2 - 3 } & 0.79 & 1.69 \\
\hline 42\% weight gain & 0.98 & 1.3 \\
\hline $58.27 \%$ weight gain & \multicolumn{2}{|c|}{$0-120 \mathrm{~V}$} \\
\cline { 2 - 3 } & \multicolumn{2}{|c|}{0.99} \\
\hline
\end{tabular}

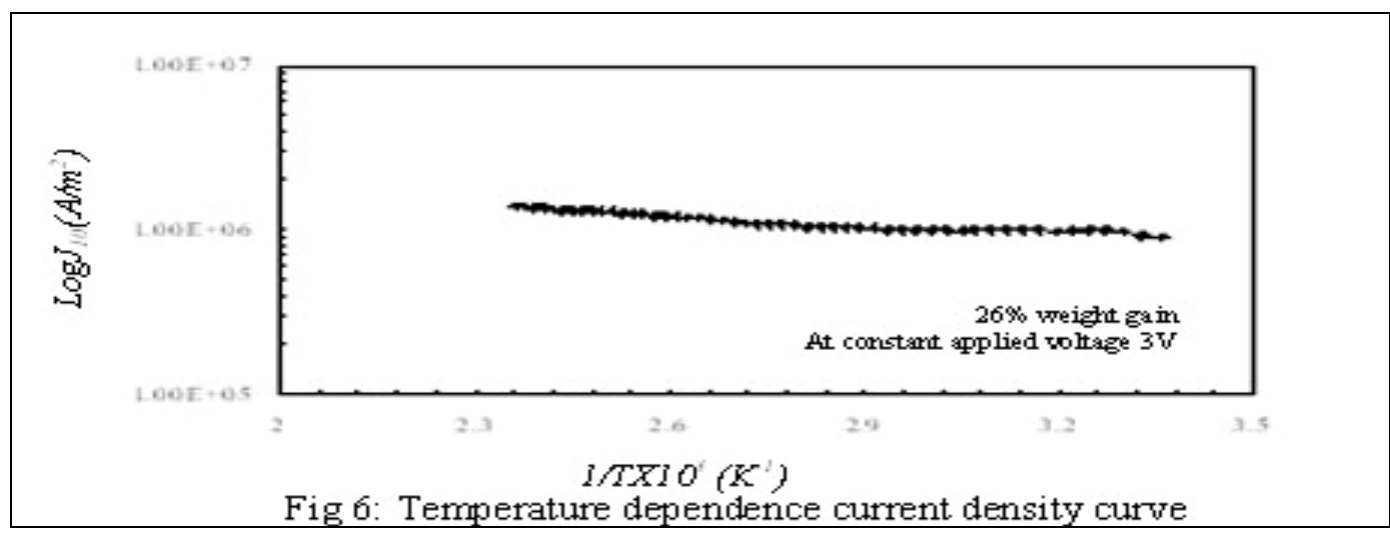

The value of $n$ is close to unity. This means that the contact is ohmic. ' $n$ ' decreases with increasing weight gain. (Table 3).

\subsection{Current Density - Temperature Characteristics}

The applied voltage was kept at constant value of $100 \mathrm{~V}$ for $58.27 \%$ weight gain sample and $3 \mathrm{~V}$ for $42 \%$ and $26 \%$ weight gain samples. Current density as a function of temperature of $26 \%$ weight gain sample is shown in Fig 6. From this Fig. 6, it is observed current density increases with increasing temperature. Value of activation energies (E) were calculated from the relation $\mathrm{J}=$ $\mathrm{J}_{\mathrm{o}} \exp (-\mathrm{E} / \mathrm{kT})$. The activation energy of $26 \%$ weight gain sample is $0.078 \mathrm{eV}$.

Current density vs. temperature curve for $42 \%$ weight gain ample as shown in Fig. 7 (a). It is found that current density increases with temperature. The activation 


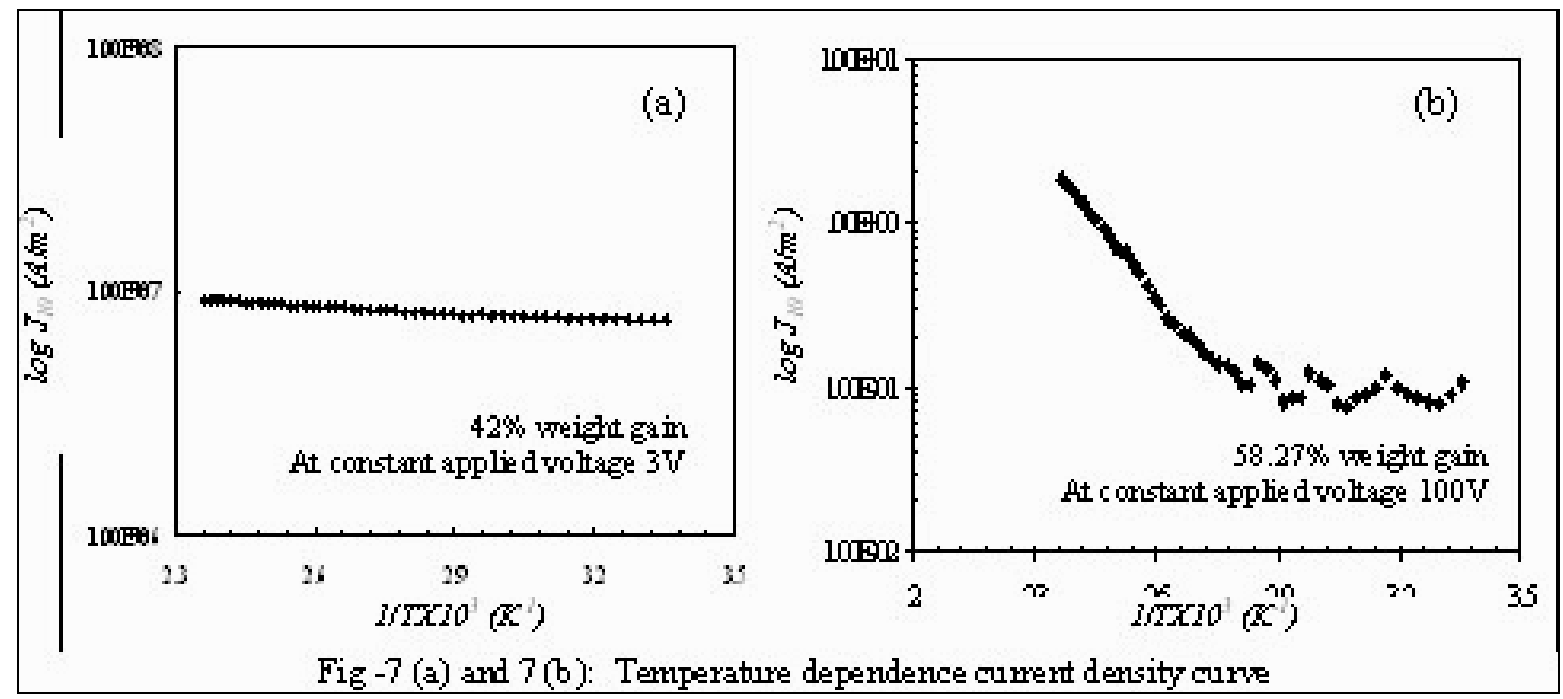

energy of this sample is $0.03 \mathrm{eV}$. and also weakly dependent on temperature. Log $\mathrm{J}$ vs. (1/Tx $\left.10^{3}\right)$ curve for $58.27 \%$ weight gain is shown in Fig. 7 (b). It is observed that current density increases with increasing temperature. At lower temperature, the current density weakly increases with increasing temperature. The activation energy in the higher temperature region is $0.83 \mathrm{eV}$ and in the lower temperature region is $0.052 \mathrm{eV}$. The activation energy is related to the formation of carriers. At lower temperature the conduction may be due to conduction through defects states and at higher temperature the conduction may be due to electronic conduction.

\subsection{A.C. Conductivity-Frequency Characteristics}

A.C. conductivity $\left(\sigma_{\mathrm{ac}}\right)$ as a variation of frequency for $26 \%$ weight gain sample is shown in Fig. 8 (a). From this Fig. it is observed that $\sigma_{a c}$ increases with increasing frequency and is weakly dependent on temperature. The values obtained over the frequency range $5 \mathrm{~Hz}-13 \mathrm{MHz}$. A.C. conductivity $\left(\sigma_{\mathrm{ac}}\right)$ vs. frequency curve for $42 \%$ weight gain sample is shown in Fig. 8 (b). It is found that a.c conductivity is almost independent of frequency. A.C. Conductivity is slightly increases with increasing temperature.
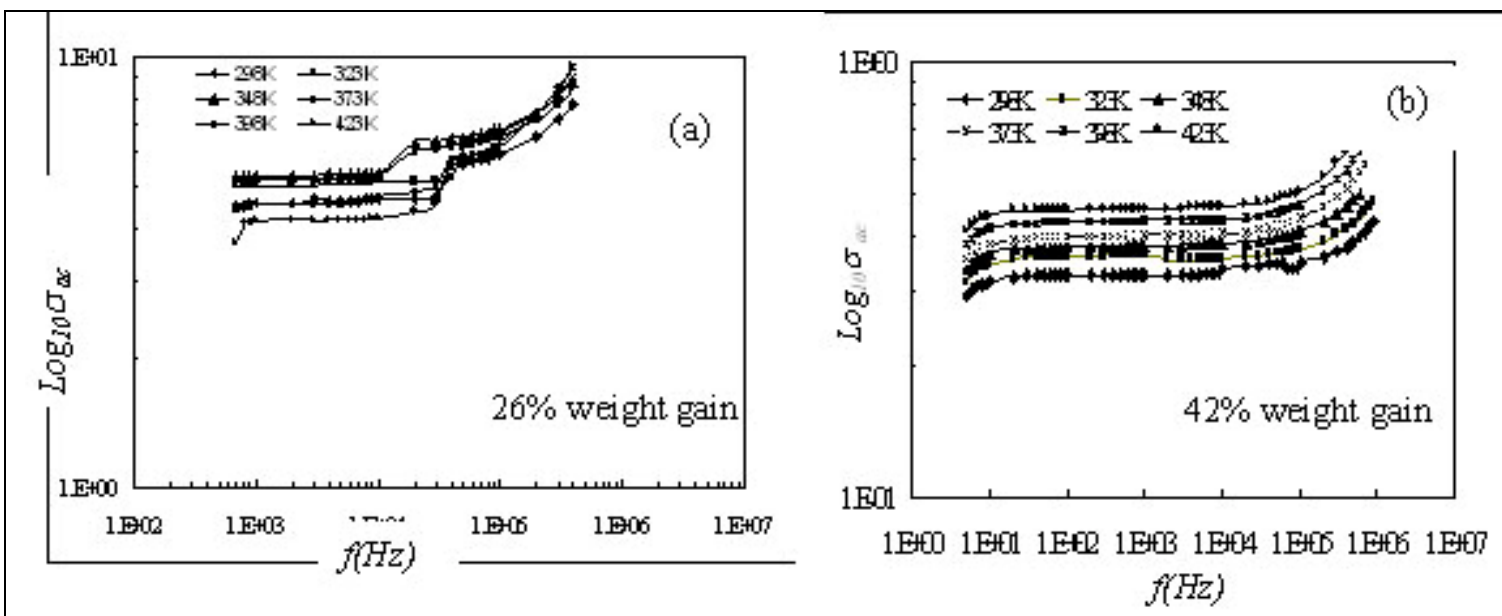

Fig-8 (a) and (b): Conductivity as a function of frequency 

In the entire sample the $\sigma_{\mathrm{ac}}$ may be affected by frequency at high frequencies. From these experimental graphs it is also found that a.c. conductivity increases with decreasing weight gain. There is a large amount of uncreated free silicon owing to the inability of nitrogen to reach the remaining silicon as the reaction progresses. Reduction of the degree of nitridation caused progressive increase in a.c. conductivity. The low conductivity material follows $\sigma_{\mathrm{ac}} \propto \omega^{\mathrm{n}}$ where $0.7<\mathrm{n}<1$. These samples are weakly dependent on ' $n$ '. For this reason the a.c. conductivity is independent on frequency.

\section{Conclusions}

X-ray diffraction (XRD) was recorded to calculate the lattice parametes and to see the effect of nitridation, on RBSN samples. The variation of current density with voltage and temperature was measured for d.c. measurement. The a.c. electrical properties such as a.c. conductivity, dielectric constant and dielectric loss factor as functions of frequency were investigated. The following conclusions are made from the present research work. From SEM micrographs of different weight gain samples, it is observed that the porosity decreases with increasing weight gain and the surface of the samples become smother. The current density -voltage characteristics of different weight gain RBSN samples is ohmic in nature. The current density of different weight gain RBSN samples is weakly dependent on temperature. A.C conductivity $\sigma_{\mathrm{ac}}$ is weakly dependent of frequency for higher weight gain samples. A.C conductivity increases with decreases weight gain, less degrees of nitridation increases a.c. conductivity and is weakly dependent on temperature. The dielectric constant for higher degrees of nitridation samples is weakly dependent on frequency and is slightly increases by a step from $298 \mathrm{k}$ to $348 \mathrm{k}$ and becomes independent of temperature. The effects of both frequency and temperature variation are noticeably smaller on dielectric constant. This implies that the carriers make a relatively small contribution to $\varepsilon^{\prime}$. Dielectric loss factor in the higher frequency range is independent of frequency Dielectric constant and loss factor increases progressively with reduction of the degrees of nitridation. Less weight gain indicating that there is a large amount of uncreated free silicon.

\section{References}

[1] Huabin Wang, Jie-Cai Hun, Shanyi Du, "Effect of nitrogen Pressure and oxygen-containing impurities on self-propagating high temperature synthesis of $\mathrm{Si}_{3} \mathrm{~N}_{4}$ ”,J. European Ceramic Society,21 (2001) 297302.

[2] Joo-Sin Lee, Ji-Hun Mun, Byung-Dong Han, Hai-Doo Kim, Byoung-Chul shin, Ll-Soo Kim, "Effect of raw$\mathrm{Si}$ particle size on the properties of sintered reaction bonded silicon nitride",

[3] John A. Mangels, Gerald J.Tennenhouse, "Densification of Reaction bonded silicon nitride", Ceramic bulletin, 59 ( 12)1980.

[4] Moulson, A.J., "Review: reaction bonded silicon nitride: its formation and properties”. J. Mater. Sci., .141 (1979) 1017-1051

[5] Joo - Sin lee, Ji- Hun Mun, Byung-dong Hun, HainDoo Kim, "Effect of $-\mathrm{Si}_{3} \mathrm{~N}_{4}$ Seed particles on the property of sintered Reaction bonded silicon nitride", Ceramics international 29 (2003) 897- 907

[6] Melendez-Martinez J.J., A.DominguezRodrigulz,"Creep of Silicon nitride”, Progress in Materials science,. 49 (2004) 19-107

[7] Berroth Karl, Prescher Torston, "Development and Industrial application of Silicon nitride Based Ceramics”,Eng. Mater.287(2005)3-9

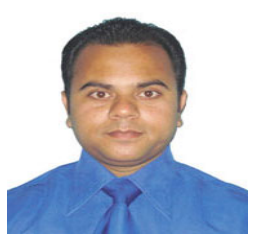

Md. Abul Hasanat Rubel has completed his B.Sc. (Hons) and M.Sc. in Physics from the Jagannath University and M.Phil. from the Bangladesh Engineering University and Technology (BUET) in 2011. Now he is working in Jagannath University, Dhaka, Bangladesh as a lecturer since 1998. He has published 3 research papers in national journals.

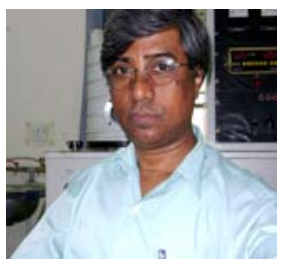

Dr. Md. Abu Hashan Bhuiyan was born at Netrakona, Bangladesh on 30th June, 1953. He obtained his B.Sc. in 1973 and M. Sc. and M. Phil. in Physics in 1975 and 1981 respectively from the Department of Physics, University of Dhaka, Bangladesh. He joined the Department of Physics, Bangladesh University of Engineering and Technology (BUET), Dhaka, Bangladesh as a Lecturer in 1981. He received his $\mathrm{Ph}$. D. degree in Physics 
from the University of Poona, India in 1989. He became Assistant Professor, Associate Professor and Professor in 1985, 1994 and 1998 respectively. He has been working in the field of Polymer physics and composite materials since 1985. He worked as a Commonwealth Staff Fellow in the Interdisciplinary Research Centre (IRC) for Polymer Science and Technology, University of Leeds, UK, for one year from
October, 1997. He has supervised so far about 15 M. Sc., 20 M. Phil. and 2 Ph.D. students. His present research interests are Polymer Physics and Composite Materials. Dr. Bhuiyan is the Secretary of Bangladesh Physical Society (Visit BPS Website) for 2004-2007. The BPS is organizing an Annual Conference in December, 2006. 